\title{
Sliding Mode Variable Structure Control for Surface Permanent Magnet Synchronous Motors Based on a Fuzzy Exponential Reaching Law
}

\author{
Lili Mo $\mathbb{D},{ }^{1,2}$ Yongqiang Liu $\mathbb{D},{ }^{2}$ and Yan Zhang $\mathbb{D}^{2,3}$ \\ ${ }^{1}$ Architectural, Design, and Research Institute, South China University of Technology, Guangzhou 510640, Guangdong, China \\ ${ }^{2}$ School of Electric Power, South China University of Technology, Guangzhou 510640, Guangdong, China \\ ${ }^{3}$ Teacher Development and Education Technology Center, Guangdong University of Finance and Economics, China \\ Correspondence should be addressed to Yan Zhang; zhangyan@gdufe.edu.cn
}

Received 3 December 2018; Revised 4 April 2019; Accepted 24 April 2019; Published 15 May 2019

Academic Editor: Alessandro De Luca

Copyright (C) 2019 Lili Mo et al. This is an open access article distributed under the Creative Commons Attribution License, which permits unrestricted use, distribution, and reproduction in any medium, provided the original work is properly cited.

\begin{abstract}
In order to handle heavy chattering and negative robustness caused by time-varying system parameters and external load disturbance of the speed control system, thereby having high-precision control over surface permanent magnetic synchronous machine (PMSM), this paper combines the advantages of sliding mode variable structure control (SMVSC) and fuzzy control. Firstly, a fuzzy sliding mode variable structure control (FUZZY-SMVSC) method is proposed, based on the vector control foundation framework of surface PMSM (SPMSM). It effectively reduces chattering while keeping sliding mode, according to the fuzzy rules formulated based on fuzzy control principle. Secondly, integral sliding mode surface is used and integration element is introduced into fuzzy control input, thereby reducing the static error of the conventional fuzzy control. Simulation and experimental results show that the proposed fuzzy sliding mode variable structure control reduces chattering by fuzzy reasoning and softening. Also, it still can maintain the strong robustness of sliding mode variable structure and ensures the fine dynamics of the system, against time-varying system parameters and external load disturbance.
\end{abstract}

\section{Introduction}

Surface PMSM (SPMSM) can be regarded as a special case of salient-pole PMSM. The torque of such PMSM is only linear with the q-axis current, but not with d-axis current. The control model is simple and widely applied to sectors like robotics, aerospace, precision numerically-controlled machine tools, and servo systems.

SPMSM is complex for its multiple inputs, strong coupling, nonlinearity, and variable parameters. The conventional control is easily affected by external interference and internal parameter changes, with poor robustness. Therefore, the conventional control fails to meet the requirements of high performance. In recent years, modern control theories like robust control, adaptive control, intelligent control, and sliding mode variable structure control have been applied to the design of SPMSM [1-4]. In particular, sliding mode variable structure control does not require high-precision mathematical model of the system and is not significantly subject to system parameter perturbation and external disturbance, with simple controller design. Therefore, it has been widely used in SPMSM speed control [5-9].

Chattering is the main factor that limits the application of sliding mode variable structure control [10-12]. In literature [10], chattering is reduced with the regularization of the boundary layer. In literature [11], chattering is reduced with observer adjustment (chattering is monitored with state observer to have dynamic adjustment of sliding mode variable structure control). These two methods are not the traditional variable structure control, with no more fine robustness of the variable structure control system, which causes system steady state error. In literature [12], chattering is reduced with high-order sliding mode variable structure control algorithm, but high-order sliding mode variable structure control algorithm is complex. In control laws for low-order (first- or second-order) systems, there is coupling 
of controller output signal and its derivative, which hinders the design of sliding mode variable structure control law. In literature [13-15], sliding mode variable structure control and fuzzy control are integrated to be applied to PMSM control. Sliding mode surface and control functions serve as fuzzy input and output variables in designing an adaptive sliding mode variable structure controller. Fuzzy rules are established to ensure the sliding mode conditions for the system, and sliding mode variable structure control output is softened, which effectively eliminates chattering. In literature [16], tracking error and control functions serve as fuzzy variables and fuzzy logic is used to estimate the upper and lower bounds of the model uncertainty, which effectively reduces chattering. In literature [17], other methods for reducing chattering with fuzzy control are elaborated on. In literature $[18,19]$, control laws are relatively simple, with linear sliding surface or error signal serving as the input of the fuzzy controller. The speed of the sliding surface is also uniform. When the system moves away from the switching surface, the speed is slow, causing the system dynamic response to take long time. When approaching the switching surface, the speed remains unchanged, but serious chattering is caused. Therefore, the static error of the fuzzy control is not solved. Although fuzzy control is not subject to the system model and can make full use of expert information, there are large static errors of fuzzy control. In this case, how to reduce the static error of fuzzy control deserves our attention [20]. In literature [21], fuzzy rules are streamlined to reduce the static error, but it will cause the number of rules to skyrocket, without significantly positive performance. In literature [22], different resolutions of fuzzy sets for different error levels are used to reduce the static error. However, when the deviation and deviation range vary greatly, the calculation and memory consumption will increase exponentially. In literature [23], PID fuzzy controller is used to reduce the static error, but it will reduce the dynamic performance of the system. At present, most scholars who study fuzzy sliding mode variable structure control focus on how to eliminate chattering, failing to pay attention to system response speed optimization and fuzzy control static error reduction that can further improve the system's comprehensive performance. Also, few researchers apply the above methods for reducing fuzzy control static error to SPMSM fuzzy control. Compared with the previous researches, this paper proposes a new fuzzy sliding mode variable structure control strategy to adjust system speed according to the distance from the sliding surface, thereby improving the response speed of the system and reducing chattering. Moreover, integration element is introduced into fuzzy control to reduce the static error of the fuzzy control and enhance the control of the system.

First of all, the proposed fuzzy sliding mode variable structure control strategy is based on vector control foundation framework. In this paper, sliding mode variable structure control strategy is applied to the speed control system, thereby improving the robustness and control accuracy of the system and coping with time-varying system parameters, external load disturbance, poor robustness, and low control precision of surface PMSM speed control system. Secondly, in order to handle sliding mode variable structure control chattering, fuzzy control is introduced into the design of the controller, and the sliding mode surface is used as the input of the fuzzy control. Fuzzy rules are formulated based on fuzzy control principle to ensure sliding mode conditions. Also, it is aimed at accelerating the dynamic response of the system when moving away from the switching surface and making the speed closer to zero when approaching the switching surface, thereby increasing system response speed and reducing chattering. Finally, integration element is introduced into fuzzy control to reduce the static error of the fuzzy control and reduce the steady-state error of the entire control system, thereby enhancing system control. Simulation and experimental results found that the proposed fuzzy sliding mode variable structure control strategy is better than conventional sliding mode variable structure control methods in terms of high comprehensive control.

The remainder of this article is organized as follows. Section 2 describes the development of an SPMSM model. Section 3 presents the design of an SMVSC system for SPMSM based on a fuzzy sliding mode variable structure control. Section 4 presents the system simulation and experimental analysis, and Section 5 provides the conclusions.

\section{Mathematical SPMSM Model}

To simplify the analysis, the following assumptions are made to develop a mathematical SPMSM model: the saturation effect of the stator core is not taken into consideration; the airgap field follows a sinusoidal distribution; eddy and magnetic hysteresis losses are not considered; there is no damping winding on the rotor; and the permanent magnet has no damping action. Based on these assumptions, a mathematical SPMSM model is established [4].

2.1. Basic Equations for SPMSMs. A mathematical SPMSM model can be treated as a special case of salient-pole synchronous motors. Hereby, a mathematical salient-pole PMSM model is first introduced.

(1) Voltage Equation. Under the assumptions presented above, the voltage equation for a salient-pole PMSM in the $a-b-c$ three-phase static coordinate system is

$$
\begin{aligned}
& u_{a}=R_{s} i_{a}+\dot{\psi}_{a} \\
& u_{b}=R_{s} i_{b}+\dot{\psi}_{b} \\
& u_{c}=R_{s} i_{c}+\dot{\psi}_{c}
\end{aligned}
$$

where $u_{a}, u_{b}$, and $u_{c}$ represent the phase voltages of the three-phase winding $(\mathrm{V}) ; i_{a}, i_{b}$, and $i_{c}$ denote the currents of the three-phase winding $(\mathrm{A}) ; R_{s}$ refers to the resistance of each phase of the winding $(\Omega) ; \psi_{a}, \psi_{b}$, and $\psi_{c}$ indicate the flux linkages of the three-phase winding $(\mathrm{V} \cdot \mathrm{s})$.

(2) Flux Linkage Equation. The flux linkage of each phase of the winding of a salient-pole PMSM is related not only to the three-phase winding current but also to the excitation field of the permanent magnet of the rotor and the position of 
the rotor. Thus, the flux linkage equation can be expressed as follows:

$$
\begin{gathered}
\psi_{a}=L_{a a} i_{a}+M_{a b} i_{b}+M_{a c} i_{c}+\psi_{f a} \\
\psi_{b}=L_{b b} i_{b}+M_{b a} i_{a}+M_{b c} i_{c}+\psi_{f b} \\
\psi_{a c}=L_{c c} i_{c}+M_{c b} i_{b}+M_{c a} i_{a}+\psi_{f c}
\end{gathered}
$$

where $L_{a a}, L_{b b}$, and $L_{c c}$ denote the self-inductances of the three phases of the winding, respectively $(\mathrm{H}) ; M_{a b}, M_{a c}$, $M_{b a}, M_{b c}, M_{c b}$, and $M_{c a}$ are the mutual inductances between any two phases of the winding $(\mathrm{H})$. The self-inductance and mutual inductance satisfy the following respective relationships:

$$
\begin{aligned}
& L_{a a}=L_{\sigma}+L_{0}+L_{2} \cos 2 \theta_{e} \\
& L_{b b}=L_{\sigma}+L_{0}-L_{2} \cos \left(2 \theta_{e}+\frac{2}{3} \pi\right) \\
& L_{c c}=L_{\sigma}+L_{0}-L_{2} \cos \left(2 \theta_{e}-\frac{2}{3} \pi\right) \\
& M_{a b}=M_{b a}=-\frac{1}{2} L_{0}-L_{2} \cos \left(2 \theta_{e}-\frac{2}{3} \pi\right) \\
& M_{b c}=M_{c b}=-\frac{1}{2} L_{0}-L_{2} \cos \left(2 \theta_{e}\right) \\
& M_{c a}=M_{a c}=-\frac{1}{2} L_{0}-L_{2} \cos \left(2 \theta_{e}+\frac{2}{3} \pi\right)
\end{aligned}
$$

where $L_{\sigma}$ indicates the leakage inductance of the stator winding $(\mathrm{H}) ; L_{0}$ represents the average main inductance $(\mathrm{H})$; $L_{2}$ refers to the second harmonic amplitude of the main inductance $(\mathrm{H}) ; \theta_{e}$ is the electrical angle between the axis of the phase $a$ of the winding and the axis of the fundamental wave magnetic field of the permanent magnet (rad).

The parameters $\psi_{f a}, \psi_{f b}$, and $\psi_{f c}$ indicate the flux linkages of the permanent magnet interlinked with the threephase winding $(\mathrm{V} \cdot \mathrm{s})$ and satisfy the following:

$$
\begin{aligned}
& \psi_{f a}=\psi_{f m} \cos \theta_{e} \\
& \psi_{f b}=\psi_{f m} \cos \left(\theta_{e}-\frac{2}{3} \pi\right) \\
& \psi_{f c}=\psi_{f m} \cos \left(\theta_{e}+\frac{2}{3} \pi\right)
\end{aligned}
$$

where $\psi_{f \mathrm{~m}}$ is defined as the amplitude of the flux linkage of the permanent magnet $(\mathrm{V} \cdot \mathrm{s})$.

(3) Torque Equation. Based on the principle of linear magnetic circuits, the stored energy $W_{m}$ and co-energy $W_{m}$ of a magnetic field are

$$
W_{m}=W_{m}^{\prime \prime}=\frac{1}{2} \mathrm{i}^{T} \psi_{f}
$$

Thus, the electromagnetic torque equation is as follows:

$$
T_{\mathrm{e}}=\frac{\partial W_{m}}{\partial \theta_{m}}=\frac{1}{2} n_{p} i^{T} \frac{\partial \psi_{f}}{\partial \theta_{r}}=\frac{1}{2}\left[i_{a} \psi_{f a}+i_{b} \psi_{f b}+i_{c} \psi_{f c}\right]
$$

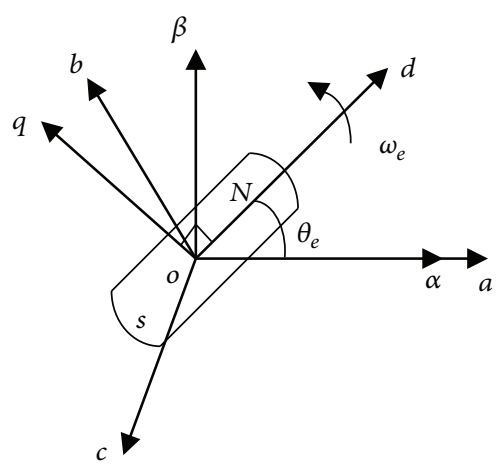

Figure 1: The $\alpha-\beta$ and $d-q$ coordinate systems.

(4) Kinematic Equation. The kinematic equation of a motor drive system is as follows:

$$
T_{e}=T_{L}+\frac{J}{p_{n}} \frac{d \omega_{e}}{d t}+\frac{B}{p_{n}} \omega_{e}+\frac{K}{p_{n}} \theta_{e}
$$

where $T_{L}$ represents the load torque $(\mathrm{N} \cdot \mathrm{m})$; $J$ defined as the moment of inertia of the system $(\mathrm{Kg} \cdot \mathrm{m} 2) ; p_{n}$ denotes the number of pole pairs; $B$ is the friction coefficient, which is positively correlated with the rotational speed $(\mathrm{N} \cdot \mathrm{m} \cdot \mathrm{s})$; and $K$ refers to the elastic twisting torque coefficient $(\mathrm{N} \cdot \mathrm{m} / \mathrm{rad})$.

2.2. $d$-q-Axis Mathematical Salient-Pole PMSM Model. To establish a $d$ - $q$-axis mathematical salient-pole PMSM model, the axis of the fundamental wave magnetic field of the permanent magnet of the rotor is set as the $d$-axis, and the $q$-axis is located at an electrical angle of $90^{\circ}$ with the counter-clockwise advance axis. A $d-q$ two-phase rotating coordinate system is thus established. In addition, by allowing the $\alpha$-axis to coincide with the $a$-axis, the $\alpha$ - $\beta$ two-phase static coordinate system is established. Figure 1 presents the established coordinate system. In addition, it shows the electrical angular rotational speed of the motor rotor (i.e., the derivative of the electrical angle $\theta_{e}$ of the motor).

(1) Voltage Equation. In the $d$ - $q$ coordinate system, the voltage equation for a salient-pole PMSM is as follows:

$$
\begin{aligned}
& u_{d}=R_{s} i_{d}+\dot{\psi}_{d}-\omega_{e} \psi_{d} \\
& u_{q}=R_{s} i_{q}+\dot{\psi}_{q}+\omega_{e} \psi_{q}
\end{aligned}
$$

where $u_{d}$ and $u_{q}$ represent the components of the voltage of the stator in the $d$ - and $q$-axes, respectively (V); $i_{d}$ and $i_{q}$ indicate the components of the current of the stator in the $d$ and $q$-axes, respectively (A); $\psi_{d}$ and $\psi_{q}$ are the components of the flux linkage in the $d$ - and $q$-axes, respectively $(\mathrm{V} \cdot \mathrm{s}) ; \omega_{e}$ refers to the electrical angular speed $(\mathrm{rad} / \mathrm{s})$.

(2) Flux Linkage Equation. In the $d$-q coordinate system, the flux linkage equation for a salient-pole PMSM is as follows:

$$
\begin{aligned}
& \psi_{d}=L_{d} i_{d}+\psi_{f} \\
& \psi_{q}=L_{q} i_{q}
\end{aligned}
$$


where $\psi_{f}=\sqrt{3 / 2} \psi_{f m} ; L_{d}$ and $L_{q}$ represent the equivalent inductances of the stator winding in the $d$-and $q$-axes, respectively $(\mathrm{H})$, which satisfy the following:

$$
\begin{aligned}
& L_{d}=L_{\sigma}+\frac{3}{2}\left(L_{0}-L_{2}\right) \\
& L_{q}=L_{\sigma}+\frac{3}{2}\left(L_{0}+L_{2}\right)
\end{aligned}
$$

(3) Torque Equation. In the $d$-q coordinate system, the torque equation for a salient-pole PMSM is as follows:

$$
T_{e}=p_{n}\left(\psi_{d} i_{d}-\psi_{q} i_{q}\right)=p_{n}\left[\psi_{f} i_{d}+\left(L_{d}-L_{q}\right) i_{d} i_{q}\right]
$$

where $p_{n}$ stands for the number of pole pairs.

(4) Kinematic Equation. The mechanical kinematic equation for a salient-pole PMSM drive system is as follows:

$$
\mathrm{J} \frac{\mathrm{d} \omega}{\mathrm{dt}}=T_{e}-T_{L}-B \omega
$$

where $T_{L}$ denotes the load torque $(\mathrm{N} \cdot \mathrm{m}) ; B$ refers to the friction coefficient $(\mathrm{N} \cdot \mathrm{m} \cdot \mathrm{s})$; $\omega$ indicates the mechanical angular speed of the motor rotor $\left(\omega=\omega_{e} / p_{n}\right)$; J represents the moment of inertia of the system (assuming that there is an ideal rigid shaft connection between the motor and the load and that the moments of inertia of the motor and the load are $J_{\mathrm{M}}$ and $J_{L}$, respectively; $J=J_{\mathrm{M}}+J_{L}$ ).

SPMSMs are a special case of salient-pole PMSMs. The inductance of an SPMSM satisfies the following condition: $L_{d}=L_{q}=L$. Based on (13), the torque of an SPMSM is only related to the $q$-axis current and is unrelated to the $d$ axis current. The equation for the torque of an SPMSM is as follows:

$$
T_{e}=1.5 p_{n} \psi_{f} i_{q}
$$

The state equation for an SPMSM is as follows:

$$
\begin{aligned}
& \dot{i}_{d}=-\frac{R_{S}}{L} i_{\mathrm{d}}+p_{n} \omega i_{q}+\frac{u_{d}}{L} \\
& \dot{i}_{q}=-p_{n} \omega i_{d}-\frac{R_{S}}{L} i_{q}-\frac{1.5 p_{n} \psi_{f}}{L} \omega+\frac{u_{q}}{L} \\
& \dot{\omega}=\frac{p_{n} \psi_{f}}{j} i_{q}-\frac{B}{J} \omega-\frac{T_{L}}{J} \\
& \dot{\theta}=\omega
\end{aligned}
$$

where $\theta$ is the mechanical angular position of the motor rotor $\left(\theta=\theta_{e} / p_{n}\right)$. In this article, each algorithm for PMSMs is designed based on SPMSMs.

2.3. Principle of the Vector Control of SPMSMs. The basic principle of the vector control is as follows. Based on the magnetic field equivalence principle, a three-phase AC motor is equivalent to a direct current (DC) motor. In a magnetic field-oriented coordinate system, the current vector of the stator is decomposed into two quadrature components, namely, an exciting current that generates a magnetic flux and a torque current that generates a torque, which are then controlled separately to regulate the torque of the threephase AC motor. Considering that the flux linkage of the rotor of an SPMSM is a constant, rotor flux-oriented control is often employed to control SPMSMs. In this study, the $i_{d}=0$ current vector control method is used to linearize the electromagnetic torque and the armature current, thereby achieving decoupled SPMSM control. This method is the most simple and effective control method.

A vector control system for an SPMSM often consists of three control loops, namely, an inside current loop (ACR), a middle speed loop (ASR), and an outermost position loop. Vector control systems for SPMSMs can be tailored based on the actual application. This study is focused on a speed control system. As a result, the system is designed without position loop but with a current loop and a speed loop. The current loop is controlled by a proportional-integral controller, and the speed loop is controlled by an SMVSC system. Figure 2 shows the structural diagram of the speed vector control system for an SPMSM.

As the $i_{d}=0$ current vector control method is used, the state equation for an SPMSM is rewritten as

$$
\begin{aligned}
i_{d} & =0 \\
\frac{d i_{q}}{d t} & =\frac{1}{L}\left(-R_{S} i_{q}-1.5 p_{n} \psi_{f} \omega+u_{q}\right) \\
\frac{d \omega}{d t} & =\frac{1}{J}\left(-T_{L}+1.5 p_{n} \psi_{f} i_{q}-B \omega\right)
\end{aligned}
$$

\section{Design of a Fuzzy Sliding Mode Variable Structure Speed Controller}

3.1. Basic Problems of Sliding Mode Variable Structure Speed Controller. For the controlled system,

$$
\dot{\mathrm{x}}=f(x, u, t) \quad\left(x \in R^{n}, u \in R^{m}, t \in R\right)
$$

Determine a switching function vector: $s=s(x) x \in R^{m}$. Find the switching control function:

$$
\begin{array}{ll}
u^{+}(x) & s(x)>0 \\
u^{-}(x) & s(x)<0
\end{array}
$$

Hereby, the variable structure control is represented by $u^{+}(x) \neq u^{-}(x)$, so that the following design objectives can be met: (1) a sliding mode exists for the controlled system (existence problem); (2) all of the state points outside the switching surface $s(x)=0$ will reach it within a finite amount of time (reachability problem); and (3) sliding mode motion is asymptotically stable and exhibits excellent dynamic qualities. Control that satisfies these three conditions is referred to as SMVSC. The control system is called sliding mode variable structure control system, and the strategies, algorithms, and controllers to realize this control are collectively called sliding mode variable structure controllers. 


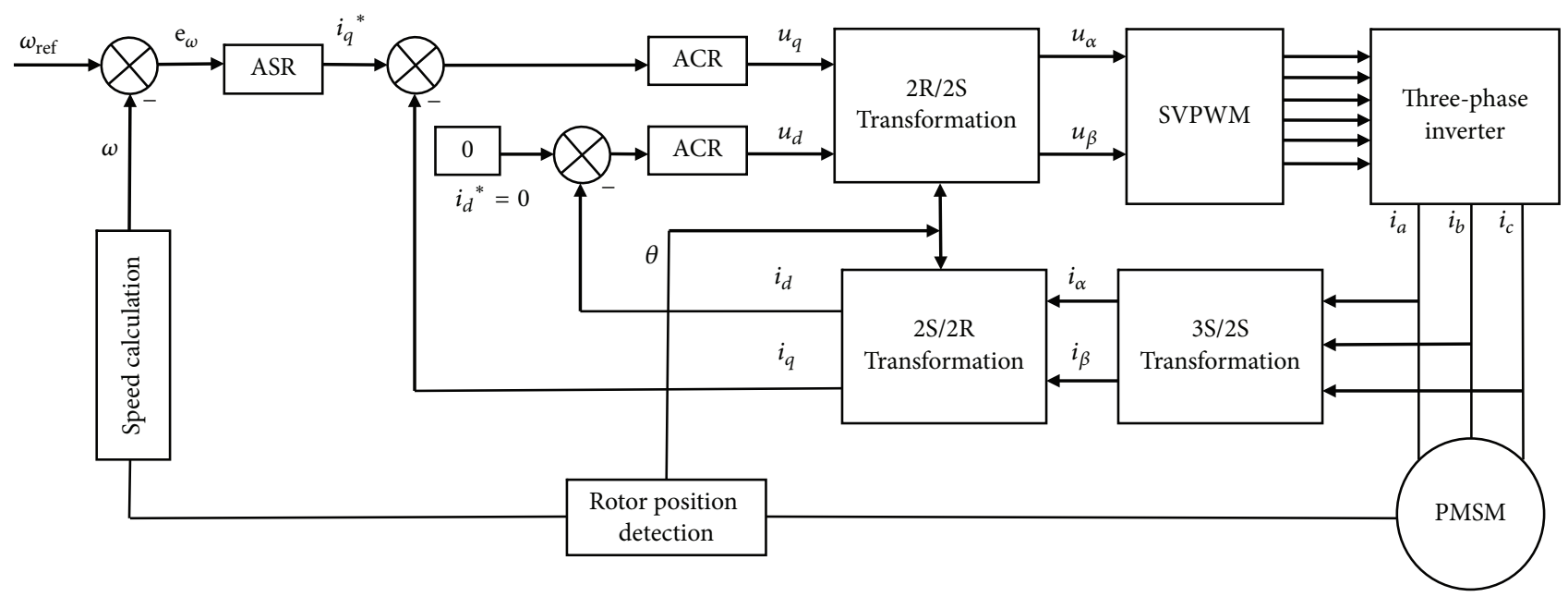

FIGURE 2: Structural diagram of the vector control system for an SPMSM.

When the system satisfies the generalized sliding mode condition $s \dot{s}<0$, the existence and accessibility conditions of the sliding mode of the system must be satisfied at the same time; that is, the system must reach the switching surface in a finite amount of time from any point in the state space, and there is no regulation on how to move.

3.2. Selection of a Sliding Mode Surface for the Fuzzy SMVSC Investigated in This Study. The system state variable is defined as the speed error:

$$
e_{\omega}=\omega_{r e f}-\omega
$$

where $\omega_{\text {ref }}$ is the reference rotational speed and $\omega$ is the actual rotational speed.

The differential of the speed error is introduced into the sliding surface selected by Liu et al. [24] and Zhang et al. [25]; therefore, high-frequency noise is easy to be introduced. To eliminate steady-state system errors, based on the conventional linear sliding mode surface, the integral of the speed error is introduced to construct an integral sliding mode surface:

$$
\mathrm{s}=e_{\omega}+\mathrm{c} \int_{0}^{t} e_{\omega} d t
$$

The following initial value $\mathrm{I}_{0}$ of the integral is selected:

$$
I_{0}=\int_{-\infty}^{0} x_{1}(\tau) d \tau=-\frac{e_{0}}{c}
$$

where $e_{0}$ is defined as the initial state of $e_{\omega} ; I_{0}$ denotes the initial value of the integral; $c$ indicates a constant coefficient (c can be set to a positive constant that allows the system to start moving on the sliding mode surface at $t=0$ and $s=0$, so the system will be globally robust). Integration can also eliminate steady-state system errors.

By letting $s=0$ and calculating the derivative of the sliding mode surface with respect to time, we have

$$
\dot{e}_{\omega}=-c e_{\omega}
$$

This equation shows demonstrates that the speed error exponentially approaches zero at a rate of a time constant $1 / c$. Therefore, the dynamic characteristics of the sliding mode motion can be determined in advance by selecting the coefficient $c$.

3.3. Determination of a Control Law for the Fuzzy SMVSC Investigated in This Study. By differentiating the sliding mode surface, we have

$$
\begin{gathered}
\dot{s}=\dot{e}_{\omega}+c e_{\omega}=\left(\dot{\omega}_{r e f}-\dot{\omega}\right)+c\left(\omega_{r e f}-\omega\right) \\
=\left[\dot{\omega}_{r e f}-\frac{1}{J}\left(-T_{L}+1.5 p_{n} \psi_{f} i_{q}-B \omega\right)\right] \\
+c\left(\omega_{r e f}-\omega\right)
\end{gathered}
$$

By letting $\dot{\boldsymbol{s}}=0$, an equivalent control is obtained:

$$
i_{e q}=\frac{1}{D}\left[c\left(\omega_{r e f}-\omega\right)+\dot{\omega}_{r e f}+\frac{B}{J} \omega+\frac{T_{L}}{J}\right]
$$

where $D=1.5\left(p_{n} \psi_{f} / J\right)$.

When a system satisfies the generalized sliding mode condition of sis $<0$, it will satisfy the existence and reachability conditions for the sliding mode; i.e., the system will definitely arrive at the switching surface from any point in the state space within a finite amount of time. There are no requirements for how the system moves. Various reaching laws can be designed to improve the quality during the arrival period.

In the exponential reaching law (ERL) proposed by Gao [8], the parameter design is adjusted to allow the speed of a moving point towards the switching surface to increase when it is distant from the switching surface, thereby accelerating the dynamic response of the system, and to allow the speed of a moving point to asymptotically approach zero when it is nearing the switching surface, thereby reducing chattering. 
The conventional ERL proposed by Gao is described as follows:

$$
\dot{s}=-\varepsilon \operatorname{sgn}(s)-k s, \quad(\varepsilon>0, k>0)
$$

The parameters $\varepsilon$ and $\mathrm{k}$ of this ERL each have a fixed value, and its switching function $\operatorname{sgn}(\mathrm{s})$ is a sign function. With this ERL, significant chattering will occur when the system is passing through the sliding mode surface. A fuzzy exponential reaching law (FERL) is proposed by improving Gao's ERL as follows. Based on fuzzy rules as well as the system load disturbance and the deviation of the system parameters, the parameters $\varepsilon$ and $\mathrm{k}$ of the conventional ERL are altered. In addition, the sign function $\operatorname{sgn}(\mathrm{s})$ is removed, and the switching function is defined and softened based on a fuzzy rule base for the system. With the FERL, the original advantages of SMVSC are preserved, and system chattering is also effectively suppressed.

The new ERL based on fuzzy control (i.e., FERL) is

$$
\dot{\mathrm{s}}=-\alpha_{1} \varepsilon-\alpha_{2} k s, \quad\left(\alpha_{1}>0, \alpha_{2}>0\right)
$$

where the values of $\varepsilon$ and $\mathrm{k}$ are determined based on the fuzzy control method; $\alpha_{1}$ and $\alpha_{2}$ are the gains of the fuzzy controller, the values of which selected depending on the actual situation to ensure that the input and output of the fuzzy controller are within their ranges of values.

The obtained control law for the new ERL is as follows:

$$
\begin{aligned}
& i_{q} \\
& =\frac{1}{D}\left[c\left(\omega_{r e f}-\omega\right)+\dot{\omega}_{r e f}+\frac{B}{J} \omega+\frac{T_{L}}{J}+\alpha_{1} \varepsilon+\alpha_{2} k s\right]
\end{aligned}
$$

Stability analysis:

A Lyapunov function is established:

$$
V=\frac{1}{2} s^{2}
$$

Then, according to Lyapunov stability theory, the system stability condition is

$$
\begin{aligned}
\dot{V} & =s \dot{s} \leq 0 \\
\dot{V} & =s \dot{s}=s\left\{\left[\dot{\omega}_{r e f}-\frac{1}{J}\left(-T_{L}+1.5 p_{n} \psi_{f} i_{q}-B \omega\right)\right]\right. \\
& \left.+c\left(\omega_{r e f}-\omega\right)\right\}
\end{aligned}
$$

Substituting the output $i_{q}$ of the new ERL into

$$
\dot{V}=-\left(\alpha_{1} \varepsilon s+\alpha_{2} k s^{2}\right)
$$

thus, when $k \geq 0$ and $\varepsilon s \geq 0, \alpha_{1} \varepsilon s \geq 0$ and $\alpha_{2} k s^{2} \geq 0$.

$$
\dot{V}=-\left(\alpha_{1} \varepsilon s+\alpha_{2} k s^{2}\right) \leq 0
$$

The system is asymptoticcally stable, and a sliding mode of the system exists and is reachable. Next, the conditions presented above are realized based on a fuzzy control rule base.

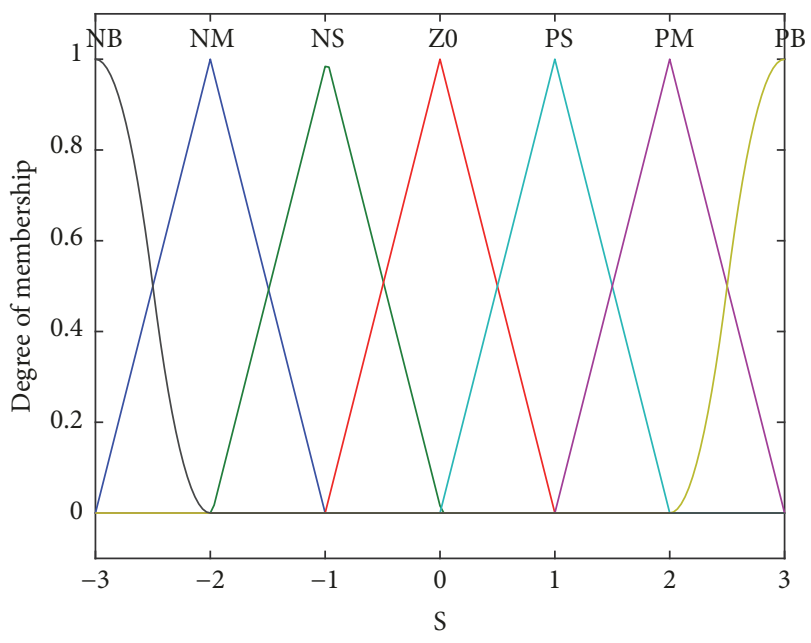

FIGURE 3: Membership function of $s_{n}$.

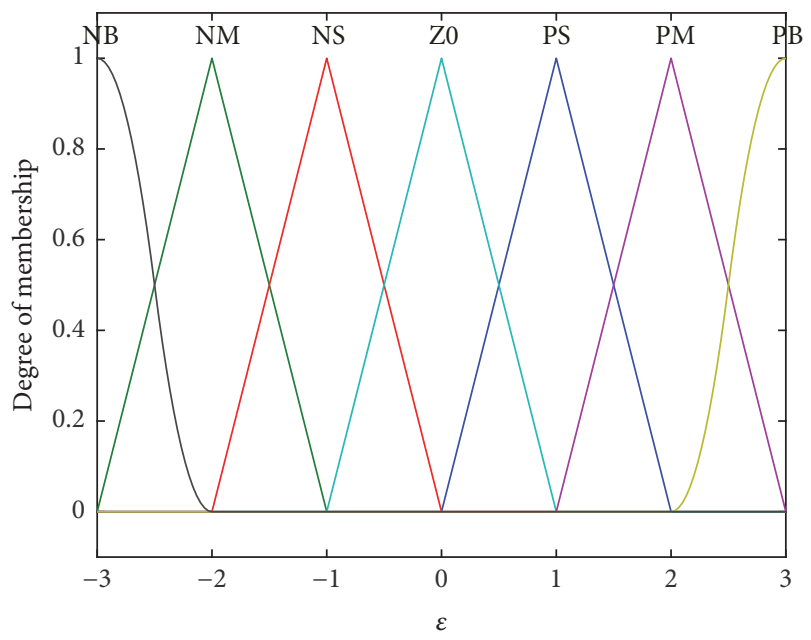

FIGURE 4: Membership function of $\varepsilon$.

Firstly, a positive constant $\sigma$ is selected, and the switching function and $s$ are normalized. It is assumed that $s_{n}=\sigma s$ is the input of the fuzzy controller and that $\varepsilon$ and $k$ are the outputs of the fuzzy controller.

Hereby, positive big (PB), positive medium (PM), positive small (PS), zero (Z0), negative small (NS), negative medium (NM), and negative big (NB) are defined as linguistic values for $s_{n}$ and $\varepsilon$, and PB, PM, and PS are defined as linguistic values for $k$.

Figures 3-5 exhibit the membership functions of $s_{n}, \varepsilon$ and $k$, respectively.

Based on the characteristics exhibited by the ERL, when the system state is relatively distant from the siding mode surface, decreasing $\varepsilon$ and increasing $k$ can accelerate the reaching process. When the system state is relatively close to the sliding mode surface, increasing $\varepsilon$ and decreasing $k$ can reduce chattering.

A fuzzy control rule base is defined, as shown in Table 1.

There are a total of seven rules, which are described in detail as follows: 


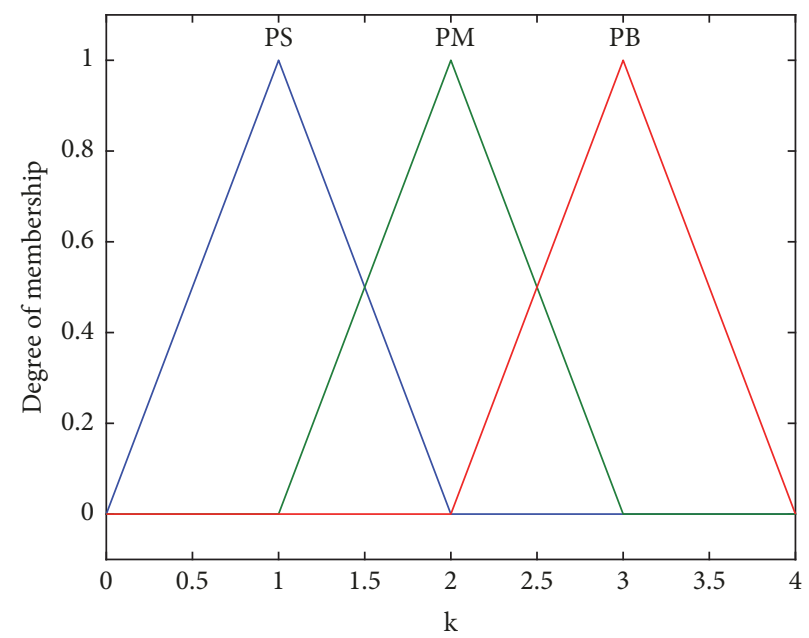

FIGURE 5: Membership function of $k$.

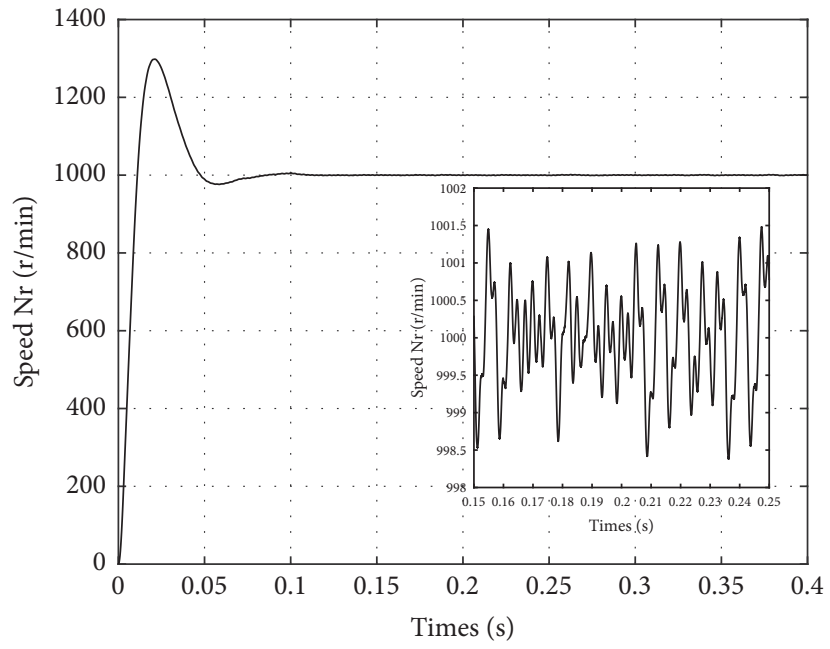

(a)

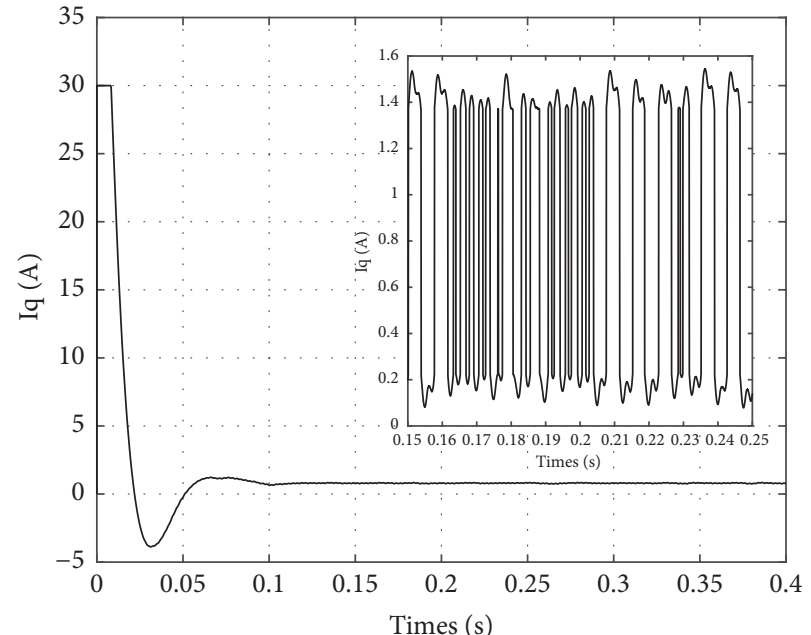

(b)

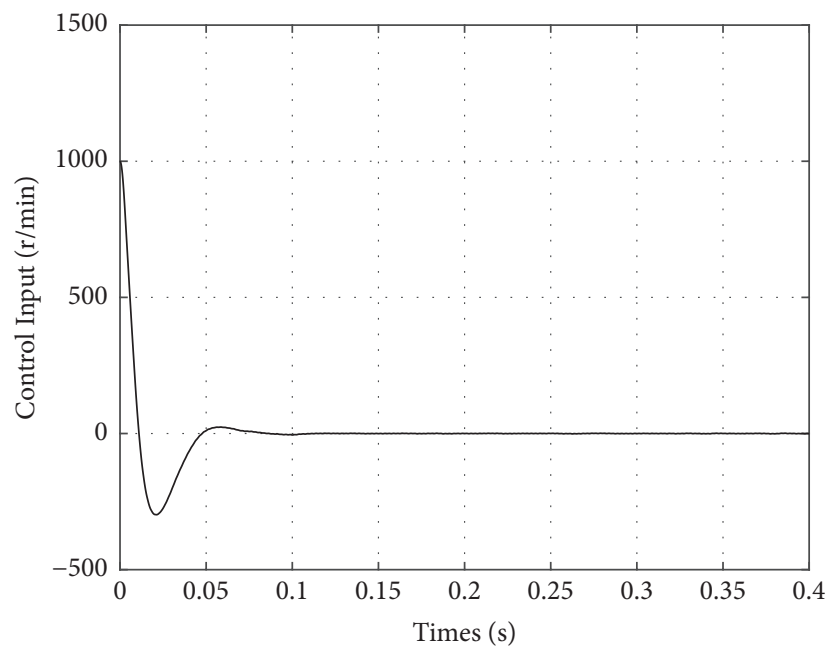

(c)

FIgURE 6: Simulation curves under the LSMVSC method. (a) Speed response, (b) $q$-axis current response, and (c) control input $e_{\omega}$ response. 


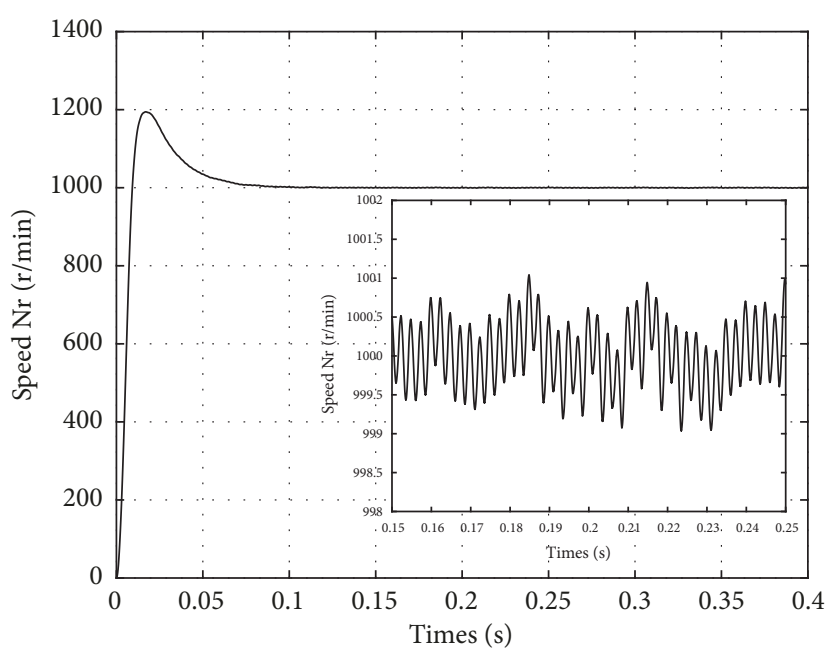

(a)

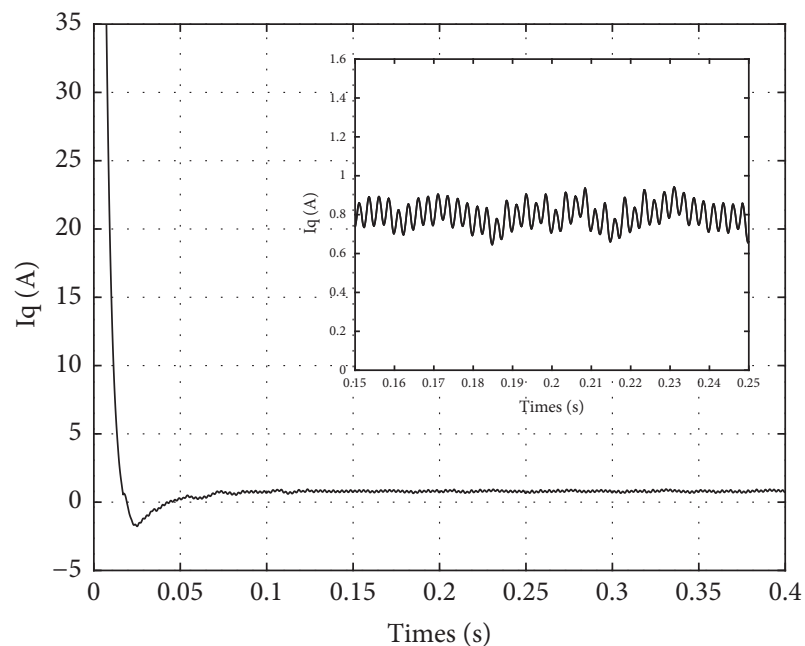

(b)

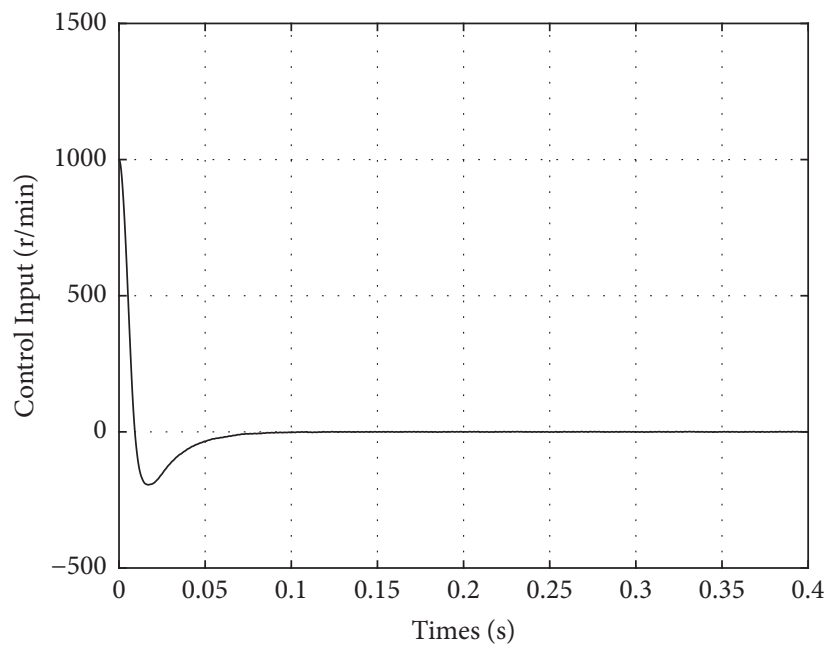

(c)

Figure 7: Simulation curves under the FUZZY-SMVSC method. (a) Speed response, (b) $q$-axis current response, and (c) control input $e_{\omega}$ response.

TABLE 1: Fuzzy control rule base.

\begin{tabular}{llllllll}
\hline & $A_{1}$ & $A_{2}$ & $A_{3}$ & $A_{1}$ & $A_{1}$ & $A_{1}$ \\
\hline$s_{n}$ & NB & NM & NS & Z0 & PS & PM & PB \\
$\varepsilon$ & PB & PM & PS & Z0 & NS & NB \\
$k$ & PS & PS & PS & PM & PB & PB \\
\hline
\end{tabular}

Rule 1: If $s_{n}=\mathrm{NB}$, then $\varepsilon=\mathrm{PB}$, and $k=\mathrm{PS}$.

Rule 2: If $s_{n}=\mathrm{NM}$, then $\varepsilon=\mathrm{PM}$, and $k=\mathrm{PS}$.

Rule 3: If $s_{n}=$ NS, then $\varepsilon=$ PS, and $k=$ PS.

Rule 4: If $s_{n}=\mathrm{ZO}$, then $\varepsilon=\mathrm{ZO}$, and $k=\mathrm{PM}$.

Rule 5: If $s_{n}=\mathrm{PS}$, then $\varepsilon=\mathrm{NS}$, and $k=\mathrm{PB}$.

Rule 6: If $s_{n}=\mathrm{PM}$, then $\varepsilon=\mathrm{NM}$, and $k=\mathrm{PB}$.

Rule 7: If $s_{n}=\mathrm{PB}$, then $\varepsilon=\mathrm{NB}$, and $k=\mathrm{PB}$.

Clearly, these fuzzy control rules ensure that the conditions that $k \geq 0$ and $\varepsilon s \geq 0$ are met. According to the sstability analysis in Section 3.3, the system is stable, and a sliding mode of the system exists and is reachable.

Based on the FERL,

When $s>0$,

$$
s(t)=\frac{\alpha_{1} \varepsilon}{\alpha_{2} k}+\left(s_{0}-\frac{\alpha_{1} \varepsilon}{\alpha_{2} k}\right) e^{-\alpha_{2} k t}
$$

When $\mathrm{s}<0$,

$$
s(t)=-\frac{\alpha_{1} \varepsilon}{\alpha_{2} k}+\left(s_{0}+\frac{\alpha_{1} \varepsilon}{\alpha_{2} k}\right) e^{-\alpha_{2} k t}
$$




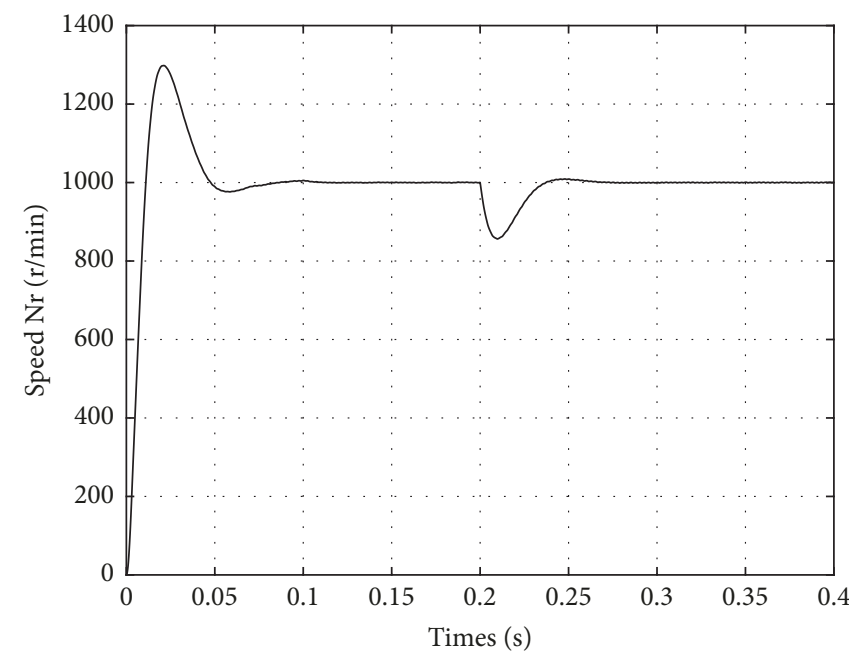

(a)

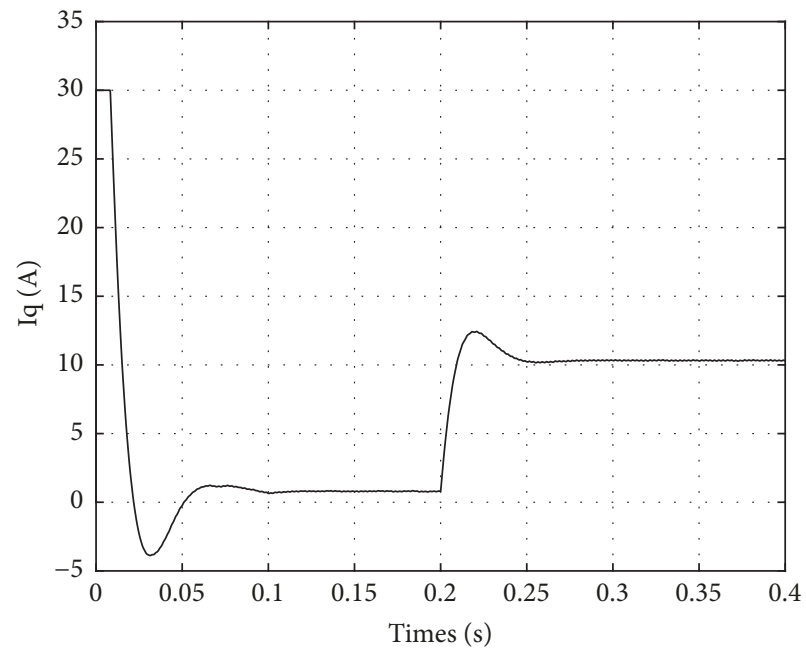

(b)

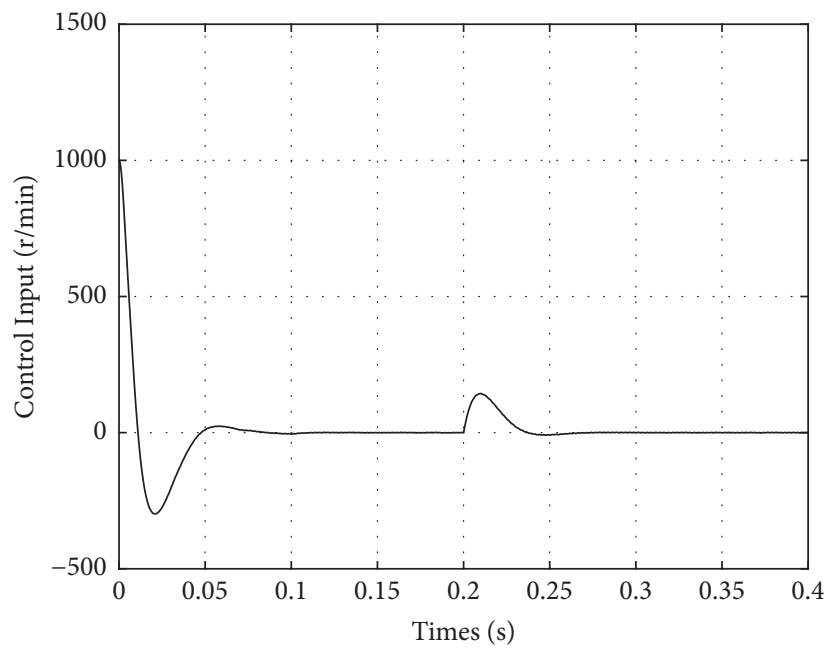

(c)

FIGURE 8: Simulation curves under the LSMVSC method when a sudden load is added. (a) Speed response, (b) $q$-axis current response, and (c) control input $e_{\omega}$ response.

The arrival time $t^{*}$ of the system is

$$
t^{*}=\frac{1}{\alpha_{2} k}\left[\ln \left(s_{0}+\frac{\alpha_{1} \varepsilon}{\alpha_{2} k}\right)-\ln \left(\frac{\alpha_{1} \varepsilon}{\alpha_{2} k}\right)\right]
$$

Thus, when the system state is distant from the sliding mode surface, a high value is selected for $\varepsilon$, which will accelerate the process where the system reaches the sliding mode surface; when the system state is getting near the sliding mode surface, a relatively low value is selected for $\varepsilon$ to reduce chattering, and the reaching time of the system is determined mainly by $k$. In this way, the performance of the system is optimized.

Defuzzification of the fuzzy outputs $\varepsilon$ and $k$ is performed using the centroid method:

$$
\begin{aligned}
& \varepsilon=\left[\sum_{j=1}^{n} \alpha_{j} \varepsilon_{j}(s)\right]\left[\sum_{j=1}^{n} \varepsilon_{j}(s)\right]^{-1} \\
& k=\left[\sum_{j=1}^{n} \beta_{j} k_{j}(s)\right]\left[\sum_{j=1}^{n} k_{j}(s)\right]^{-1}
\end{aligned}
$$

where $\alpha_{j}$ and $\beta_{j}$ are the central values of the $j^{\text {th }}$ domain of discourse.

\section{Simulation and Experimental Study}

4.1. Simulation Result Analysis. In order to validate the effectiveness of the proposed method, the SMVSC controller based on linear sliding mode surface (LSMVSC) and the FUZZY-SMVSC controller are employed in the speed loop in 


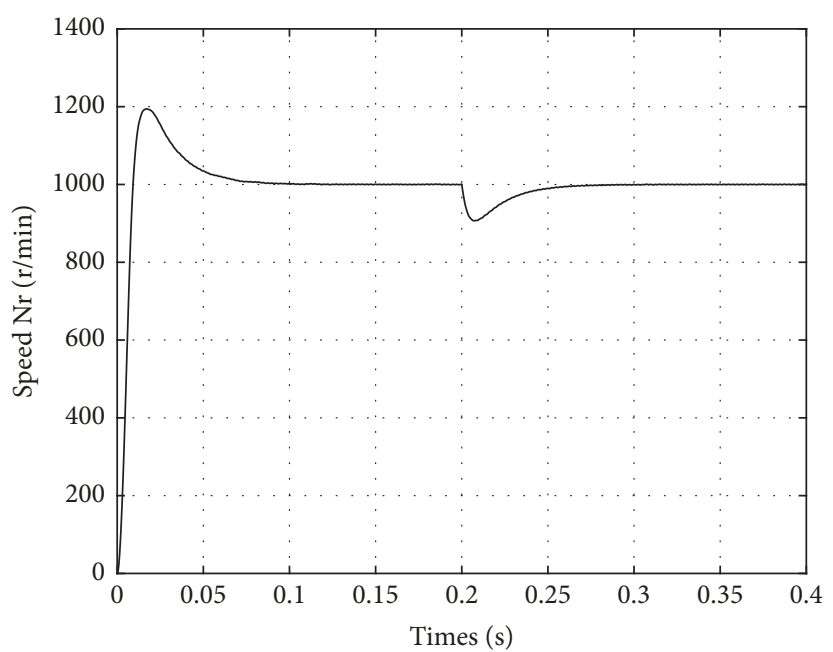

(a)

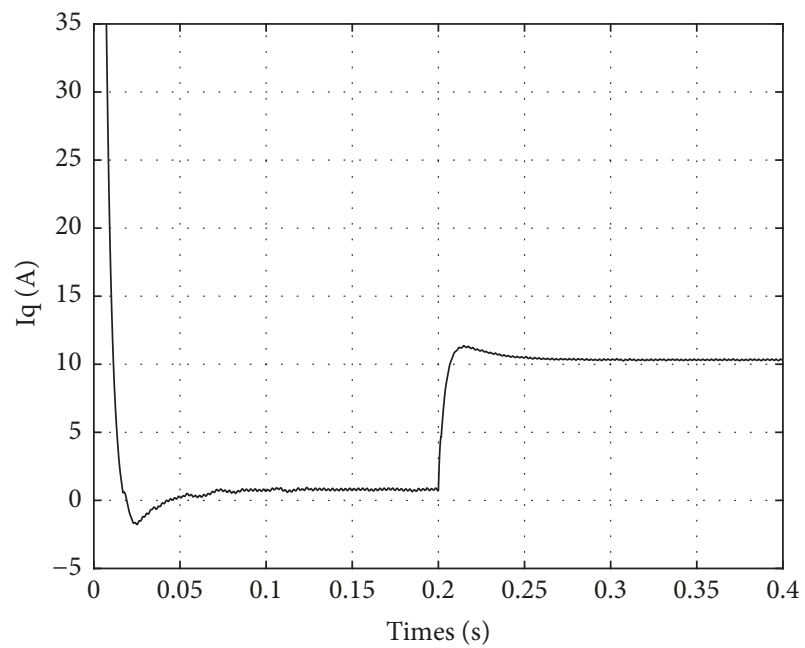

(b)

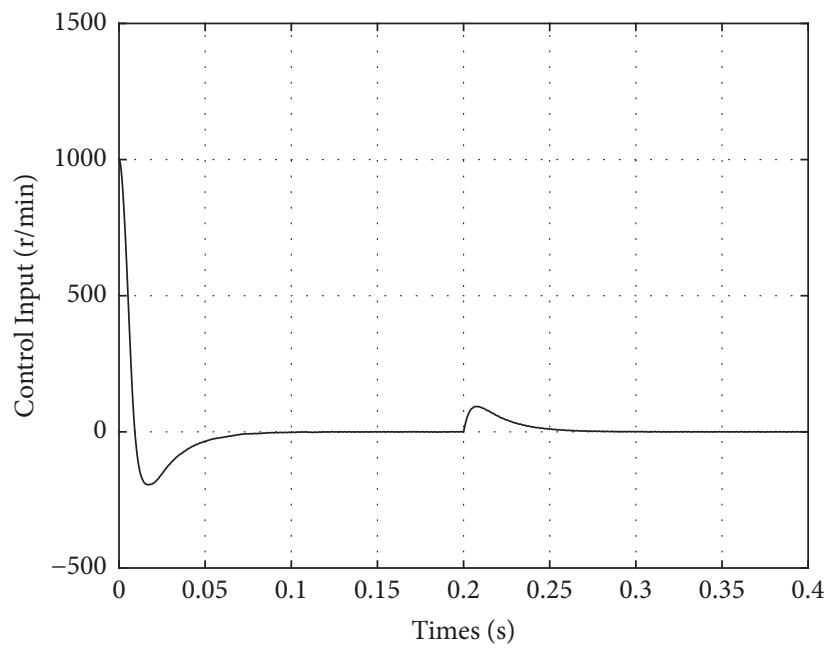

(c)

FIGURE 9: Simulation curves under the FUZZY-SMVSC method when a sudden load is added. (a) Speed response, (b) $q$-axis current response, and (c) control input $e_{\omega}$ response.

simulations and experiments. The LSMVSC controller adopts linear sliding mode surface $s=c e_{\omega}+\dot{e}_{\omega}(c>0)$ and Gao's exponential reaching law $\dot{s}=-\varepsilon \operatorname{sgn}(s)-k s,(\varepsilon>0, k>0)$, and the control law is $i_{q}=(1 / D) \int_{0}^{t}\left[c \dot{e}_{\omega}+\varepsilon \operatorname{sgn}(s)+k s\right] d \tau$. A vector control system simulation platform was developed in MATLAB/Simulink. The motor parameter settings applied to the simulation are as follows: number of pole pairs $\left(p_{n}\right): 4$; inductance of the stator $\left(L_{s}\right): 8.5 \mathrm{mH}$; resistance of the stator $(R): 2.875 \Omega$; flux linkage $\left(\psi_{f}\right): 0.175 \mathrm{~Wb}$; moment of inertia $(J): 0.003 \mathrm{~kg} \cdot \mathrm{m}^{2}$; and damping coefficient B: $0.008 \mathrm{~N} \cdot \mathrm{m} \cdot \mathrm{s}$. The system simulation conditions are as follows: DC busbar voltage $\left(U_{d c}\right): 311 \mathrm{~V}$; switching frequency $\left(f_{\text {pwm }}\right): 10 \mathrm{kHz}$; reference rotational speed $\left(N_{\text {ref }}\right): 1000 \mathrm{r} / \mathrm{min}$; initial torque $\left(T_{L}\right) 0 \mathrm{~N} \cdot \mathrm{m}$; and a load torque $T_{L}$ of $10 \mathrm{~N} \cdot \mathrm{m}$ is added at $\mathrm{T}=0.2 \mathrm{~s}$ when testing the system performance under a disturbance. The moment of inertia $(J)$ is halved or doubled when testing the system performance under the changes of parameter.
(1) Simulation Settings. The PI simulation parameters of both current loops are the same: proportional gain $k_{p}=17$ and integral gain $k_{i}=5700$. The parameters of the LSMVSC speed loop are as follows: $c=60 ; \varepsilon=200$; and $k=300$. The parameters of the FUZZY-SMVSC speed loop are as follows: $\mathrm{c}=60 ; \sigma=0.2 ; \alpha_{1}=80$; and $\alpha_{2}=200$.

(2) Simulation Results. Figures 6-11 present the simulation results.

Figures 6-7 present the simulation curves of the speed response and $\mathrm{q}$-axis current response under a speed command of $1000 \mathrm{r} / \mathrm{min}$. The simulation results indicate clearly that compared with the speed response of the LSMVSC method (30\% overshoot and $0.11 \mathrm{~s}$ adjustment time), the speed response under the FUZZY-SMVSC method has a significantly smaller overshoot $(20 \%)$ and a shorter adjustment time $(0.08 \mathrm{~s})$. Meanwhile, the $q$-axis current responds quicker and has smaller overshoot compared with that of 

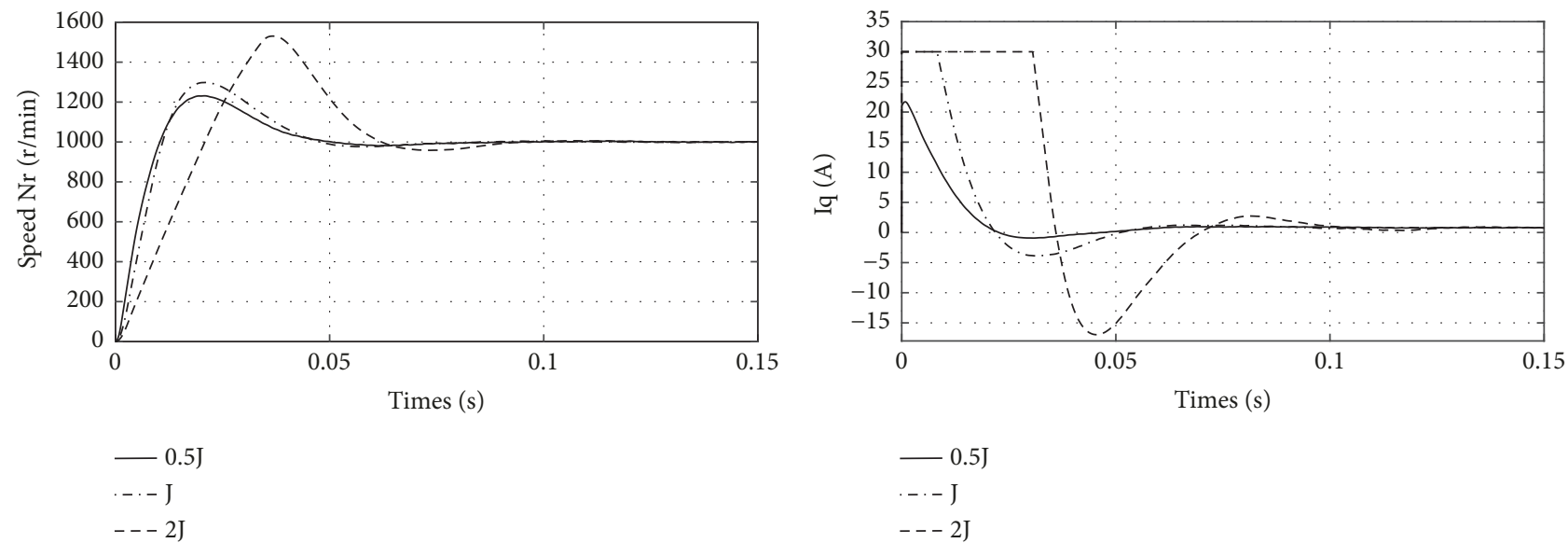

(a)

(b)

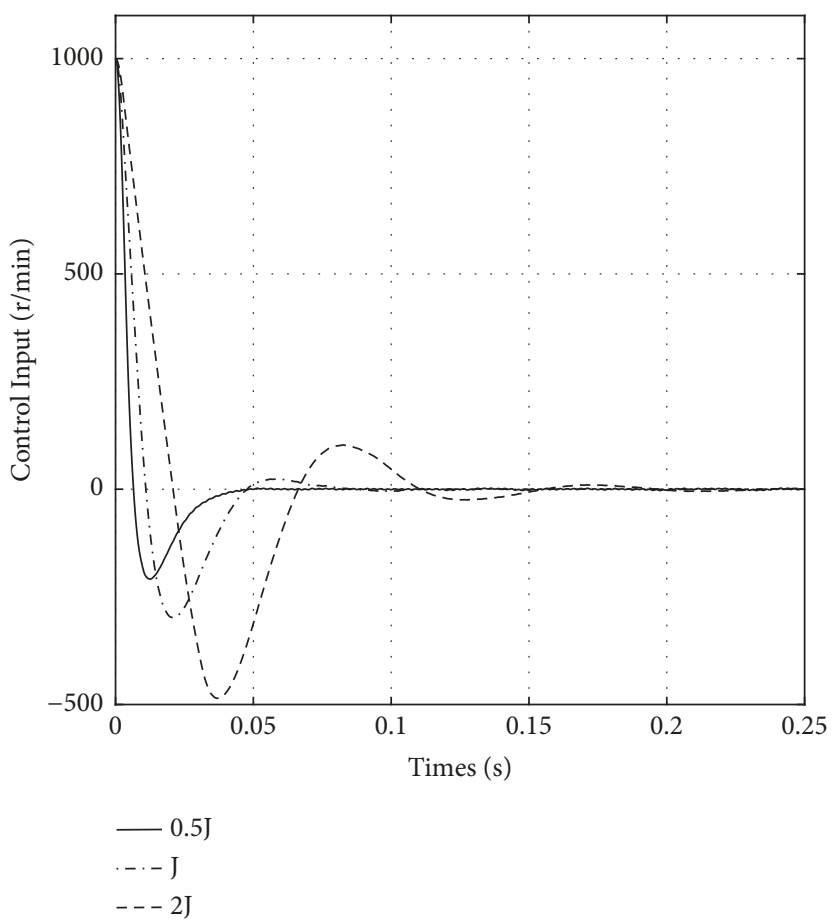

(c)

FIGURE 10: Simulation curves under the LSMVSC method when parameter perturbation injection. (a) Speed response, (b) $q$-axis current response, and (c) control input $e_{\omega}$ response.

the LSMVSC method. As compared to the LSMVSC method, the chattering is suppressed better than the FUZZY-SMVSC method.

Figures 8-9 present the simulation curves of the speed response and q-axis current response when a sudden load is added. The load disturbance $T_{L}=10 \mathrm{~N} \cdot \mathrm{m}$ is added abruptly after a time duration of $\mathrm{t}=0.2 \mathrm{~s}$. The results show that the FUZZY-SMVSC method has the less speed fluctuations and $q$-axis current fluctuations. Besides, the settling time required for the speed and $q$-axis current to return to the original value is the smaller. This demonstrates that the FUZZY-SMVSC method can deliver better system dynamic performance and robustness to disturbances than the LSMVSC methods.
Figures 10-11 indicate the simulation curves of the speed response and q-axis current response when the moment of inertia $(J)$ is halved or doubled. The results show that the FUZZY-SMVSC method has less speed fluctuations and $q$ axis current fluctuations. Besides, the settling time required for the speed and $q$-axis current to return to the original value is smaller. This demonstrates that the FUZZY-SMVSC method can deliver better system dynamic performance and robustness than the LSMVSC method when a parameter perturbation is injected.

Figures $6-11$ show that the control input $e_{\omega}$ of the FUZZYSMVSC method is less than that of the LSMVSC method in all cases. The FUZZY-SMVSC method is superior to the 

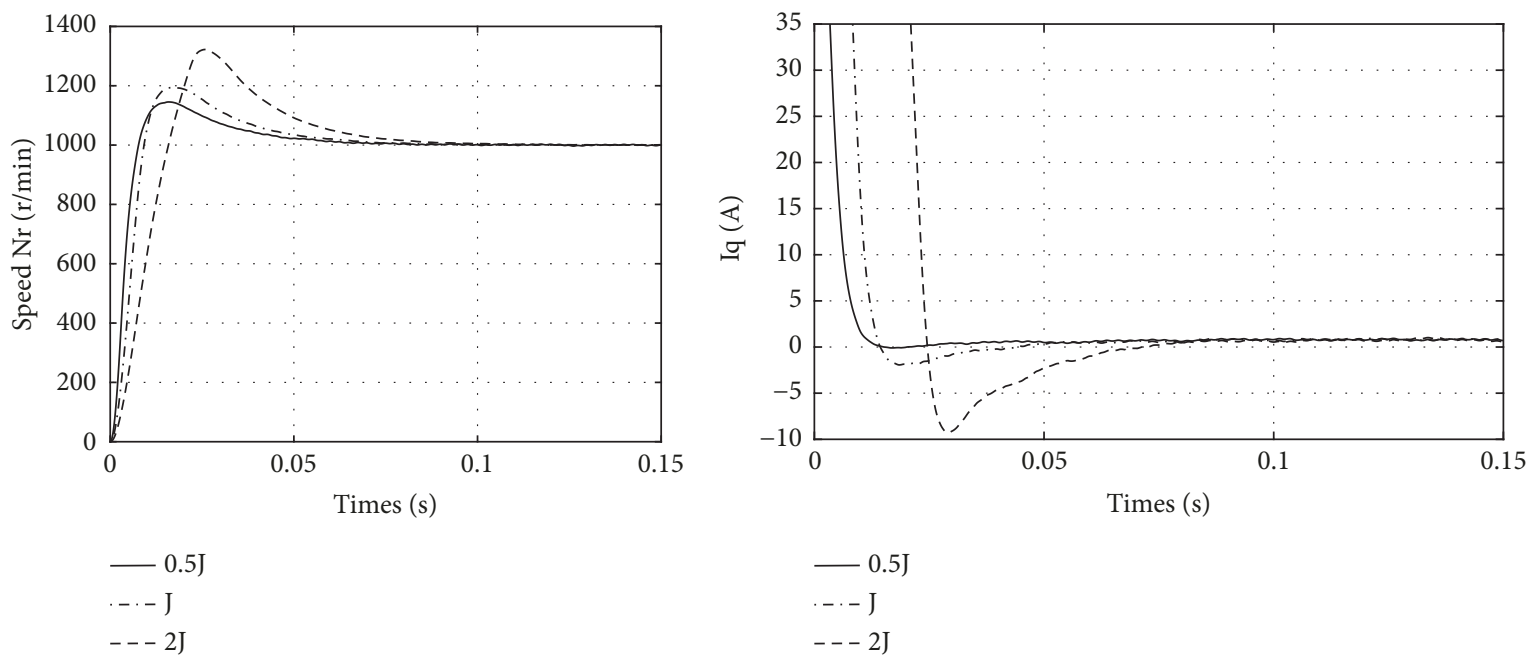

(a)

(b)

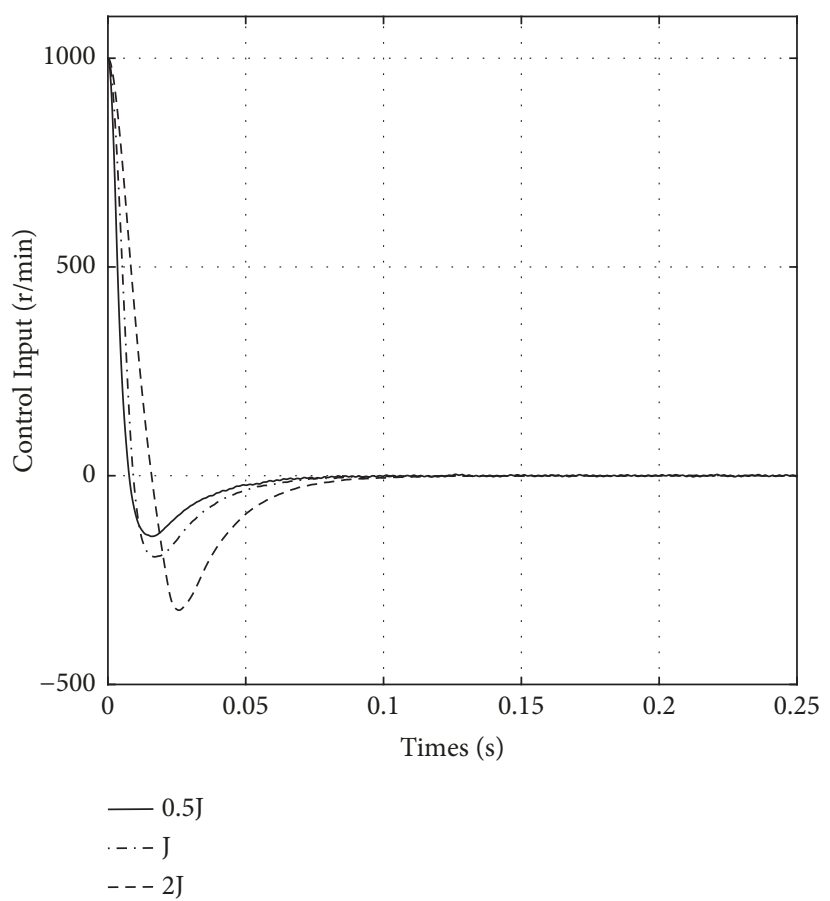

(c)

FIGURE 11: Simulation curves under the FUZZY-SMVSC method when parameter perturbation injection. (a) Speed response, (b) $q$-axis current response, and (c) control input $e_{\omega}$ response.

LSMVSC control method in response speed and control accuracy.

4.2. Experimental Result Analysis. Step response and load disturbance experiments are conducted for the proposed method to validate the reduction in chattering and robustness to disturbance of the speed controller. The hardware configuration of the PMSM drive and control system is shown in Figure 12. The experimental platform were developed using a TI DSP28335 data processor. In addition, the relevant experimental validation was performed based on this system.
The parameters of the SPMSM are as follows: number of pole pairs $\left(\mathrm{p}_{\mathrm{n}}\right): 4$; inductance of the stator $\left(\mathrm{L}_{\mathrm{s}}\right): 1.31 \mathrm{mH}$; resistance of the stator (R): $2.26 \Omega$; moment of inertia $(\mathrm{J}): 0.9 \times 10^{-4}$ $\mathrm{kg} \cdot \mathrm{m} 2$; and damping coefficient (B): $0.0057 \mathrm{~N} \cdot \mathrm{m} \cdot \mathrm{s}$. The preset rotational speed $\left(\mathrm{N}_{\text {ref }}\right)$ and initial torque $\left(\mathrm{T}_{\mathrm{L}}\right)$ of the system are $990 \mathrm{r} / \mathrm{min}$ and $0 \mathrm{~N} \cdot \mathrm{m}$, respectively. A load torque $\mathrm{T}_{\mathrm{L}}$ of $0.1 \mathrm{~N} \cdot \mathrm{m}$ is added at $\mathrm{T}=2 \mathrm{~s}$ when testing the system with a load disturbance. The PI Experimental parameters of both current loops are the same: proportional gain $k_{p}=0.3$ and integral gain $k_{i}=0.002$. The parameters of the LSMVSC speed loop are as follows: $\mathrm{c}=50 ; \varepsilon=100$; and $k=200$. The parameters of the FUZZY-SMVSC speed loop are as follows: $c=50$; 


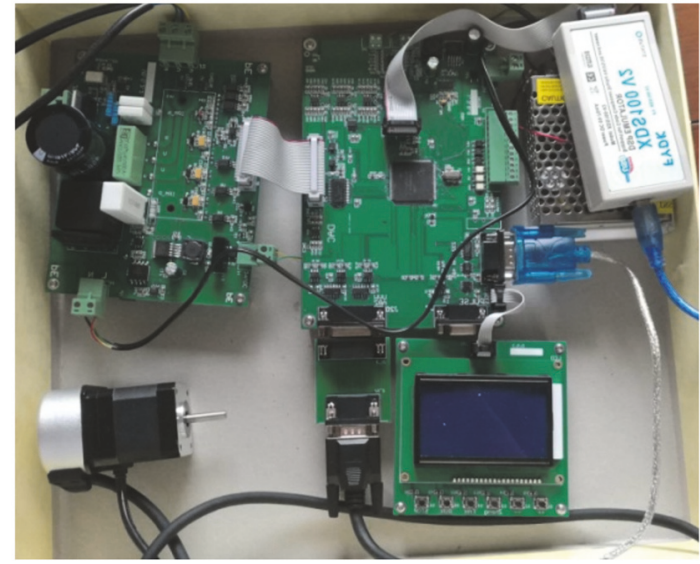

FIGURE 12: Experimental platform for the SPMSM control system.

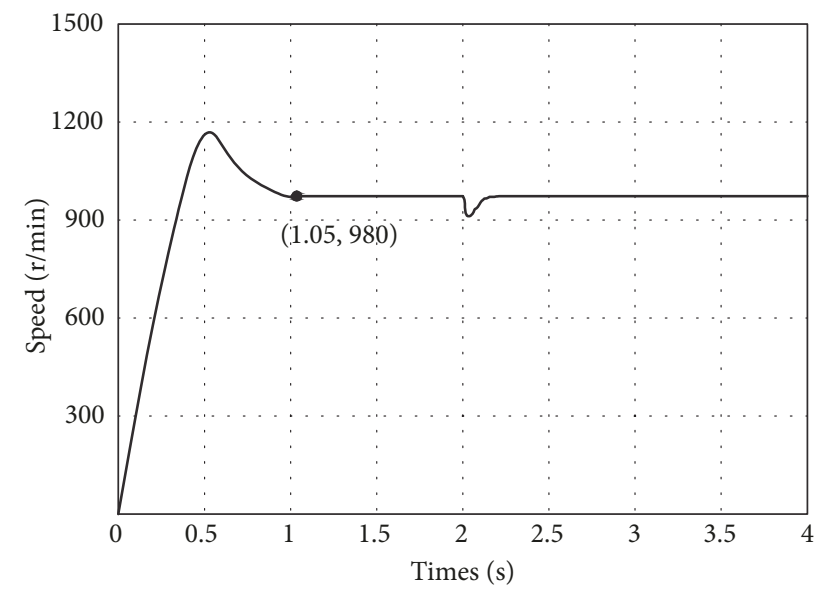

FIGURE 13: Experimental curves under the LSMVSC method: speed response.

$\sigma=0.1 ; \alpha_{1}=50$; and $\alpha_{2}=80$. Figures 13-14 show the experimental results.

The responses of the LSMVSC and FUZZY-SMVSC methods under a speed command of $1000 \mathrm{r} / \mathrm{min}$ are shown in Figures 13-14. The experimental results clearly show that the FUZZY-SMVSC method achieves a more satisfactory dynamic response than the LSMVSC method. Moreover, loading experiments were carried out to verify the disturbance robustness of the LSMVSC and FUZZY-SMVSC methods under a speed command of $1000 \mathrm{r} / \mathrm{min}$. In these tests, the load torque $\mathrm{T}_{\mathrm{L}}=0.1 \mathrm{~N} \cdot \mathrm{m}$ was added abruptly and removed after a time duration of $t=2 \mathrm{~s}$. The load disturbance was realized by a magnetic power brake. From the experimental curves, it is evident that the proposed method has a more satisfactory robustness to disturbances and exhibits less chattering than those of the LSMVSC method. The speed current of the FUZZY-SMVSC method responds more quickly and have a smaller overshoot than the FUZZYSMVSC method. This demonstrates that the FUZZY-SMVSC method can deliver better system dynamic performance and robustness to disturbances than the LSMVSC methods.

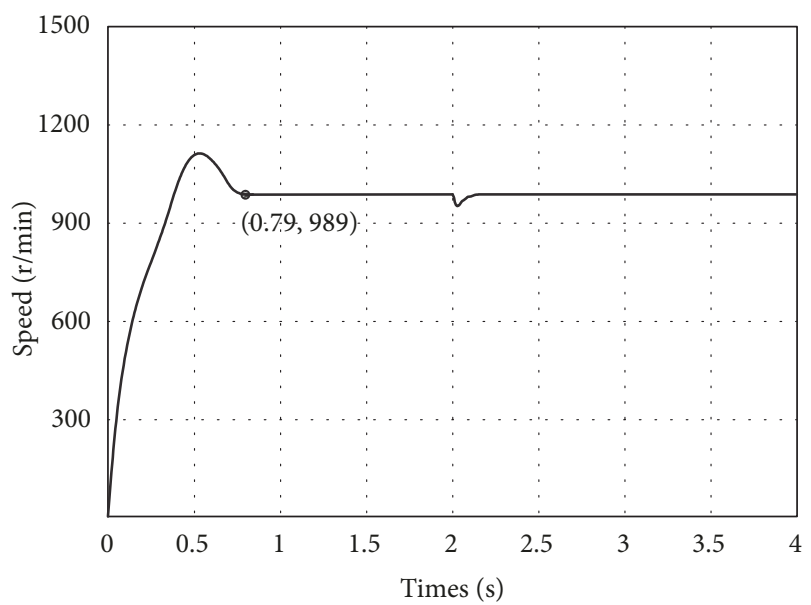

FIGURE 14: Experimental curves under the FUZZY-SMVSC method: speed response.

In summary, from these simulation and experiment results, the FUZZY-SMVSC method not only effectively addressed the chattering problem but also ensured excellent dynamic system qualities and relatively good system robustness.

\section{Conclusions}

In this study, based on the effects of temporal variations in the parameters of a SPMSM speed control system and an external load disturbance on system performance, SMVSC and fuzzy control algorithms are applied to the system to improve its performance. The main contents and contributions of this study are summarized as follows. (1) An SMVSC system design scheme is developed, in which an integral sliding mode surface and the ERL are used. (2) The ERL is improved by introducing fuzzy control and establishing a fuzzy rule base. (3) The fuzzy control and sliding mode variable structure algorithms are combined to improve the system's robustness and reduce chattering. The simulation and experimental results show that compared to the conventional LSMVSC method based on a linear sliding surface, the FUZZY-SMVSC method effectively reduced chattering, reduced static error of fuzzy control improved the dynamic and steady-state performance of the system, and allowed the system to rapidly respond and return to the preset value after a load disturbance or when parameter perturbation is injected, thereby ensuring high system robustness and excellent dynamic system qualities.

\section{Data Availability}

The data used to support the findings of this study are included within the article.

\section{Conflicts of Interest}

The authors declare that they have no conflicts of interest. 


\section{Acknowledgments}

This work was supported by the Key Projects of Social Science Planning in Foshan in 2018 under Grant No. 2018-ZDB05 and Youth Innovative Talents Project of Guangdong Provincial Education Department (HUMANITIES AND SOCIAL SCIENCES) under Grant No. 2017WQNCX055.

\section{References}

[1] R. Ramírez-Villalobos, L. T. Aguilar, and L. N. Coria, "Sensorless Ho speed-tracking synthesis for surface-mount permanent magnet synchronous motor," ISA Transactions ${ }^{\circledR}$, vol. 67, pp. 140150, 2017.

[2] S.-K. Kim, "Robust adaptive speed regulator with self-tuning law for surfaced-mounted permanent magnet synchronous motor," Control Engineering Practice, vol. 61, pp. 55-71, 2017.

[3] F. F. M. El-Sousy, "Intelligent mixed $\mathrm{H} 2 / \mathrm{Ho}$ adaptive tracking control system design using self-organizing recurrent fuzzywavelet-neural-network for uncertain two-axis motion control system," Applied Soft Computing, vol. 41, pp. 22-50, 2016.

[4] P. Xia, Y. Deng, Z. Wang, and H. W. Li, "Speed adaptive sliding mode control with an extended state observer for permanent magnet synchronous motor," Mathematical Problems in Engineering, vol. 2018, Article ID 6405923, 13 pages, 2018.

[5] M. A. M. Cheema, J. Fletcher, M. Farshadnia, and F. Rahman, "Sliding mode based combined speed and direct thrust force control of linear permanent magnet synchronous motors with first order plus integral sliding condition," IEEE Transactions on Power Electronics, vol. 34, no. 3, pp. 2526-2538, 2018.

[6] Q. Song and J. Chao, "Robust speed controller designed for permanent magnet synchronous motor drives based on sliding mode control," Science Direct, vol. 88, pp. 867-873, 2016.

[7] V. I. Utkin, "Variable structure systems with sliding modes," IEEE Transactions on Automatic Control, vol. 22, no. 2, pp. 212222, 1977.

[8] W. Gao, Variable Structure Control Theories and Design Methods, Science Publishing House, Beijing, China, 1996.

[9] S.-B. Choi, Y.-K. Park, and J.-D. Kim, "Vibration characteristics of hollow cantilevered beams containing an electro-rheological fluid," International Journal of Mechanical Sciences, vol. 35, no. 9, pp. 757-768, 1993.

[10] A. Wahyu Aditya, M. Rizani Rusli, B. Praharsena, E. Purwanto, D. Cahya Happyanto, and B. Sumantri, "The performance of FOSMC and boundary - SMC in speed controller and current regulator for IFOC-based induction motor drive," in Proceedings of the 2018 International Seminar on Application for Technology of Information and Communication (iSemantic), pp. 139-144, Semarang, Indonesia, September 2018.

[11] S.-L. Shi, J.-X. Li, and Y.-M. Fang, "Extended-state-observerbased chattering free sliding mode control for nonlinear systems with mismatched disturbance," IEEE Access, vol. 6, pp. 22952-22957, 2018.

[12] S. K. Kommuri, G. Shafiq, J. J. Rath, and K. C. Veluvolu, "Robust control of DC motor drives using higher-order integral terminal sliding mode," in Proceedings of the 14th International Conference on Control, Automation, Robotics and Vision, ICARCV 2016, pp. 1-6, Thailand, November 2016.

[13] S.-B. Choi and J.-S. Kim, "A fuzzy-sliding mode controller for robust tracking of robotic manipulators," Mechatronics, vol. 7, no. 2, pp. 199-216, 1997.
[14] L. Sheng, G. Xiaojie, and Z. Lanyong, "Robust adaptive backstepping sliding mode control for six-phase permanent magnet synchronous motor using recurrent wavelet fuzzy neural network," IEEE Access, vol. 5, pp. 14502-14515, 2017.

[15] F.-J. Lin, Y.-C. Hung, and K.-C. Ruan, "An intelligent secondorder sliding-mode control for an electric power steering system using a wavelet fuzzy neural network," IEEE Transactions on Fuzzy Systems, vol. 22, no. 6, pp. 1598-1611, 2014.

[16] J. Fei, Y. Chu, and S. Hou, "A backstepping neural global sliding mode control using fuzzy approximator for three-phase active power filter," IEEE Access, vol. 5, pp. 16021-16032, 2017.

[17] L. Hou, W. Li, H. Shen, and T. Li, "Fuzzy sliding mode control for systems with matched and mismatched uncertainties/disturbances based on ENDOB," IEEE Access, vol. 7, pp. 666-673, 2019.

[18] P. Pei, Z. Pei, Z. Tang, and H. Gu, "Position tracking control of PMSM based on fuzzy PID-variable structure adaptive control," Mathematical Problems in Engineering, vol. 2018, Article ID 5794067, 15 pages, 2018.

[19] J.-Y. Chen, "Expert SMC-base fuzzy control with genetic algorithms," Journal of The Franklin Institute, vol. 336, no. 4, pp. 589$610,1999$.

[20] X. Ouyang, A Study on a DSP-Based Sliding Mode Variable Structure Control System for Permanent Magnet Synchronous Motors, South China University of Technology, 2012.

[21] F.-J. Lin, S.-G. Chen, and I.-F. Sun, "Intelligent sliding-mode position control using recurrent wavelet fuzzy neural network for electrical power steering system," International Journal of Fuzzy Systems, vol. 19, no. 5, pp. 1344-1361, 2017.

[22] G. Calcev, "Some remarks on the stability of Mamdani fuzzy control systems," IEEE Transactions on Fuzzy Systems, vol. 6, no. 3, pp. 436-442, 1998.

[23] F. J. Song and S. Smith, "A comparison of sliding mode fuzzy controller and fuzzy sliding mode controller," in Proceedings of the 19th International Conference of the North American Fuzzy Information Processing Society, NAFIPS2000, pp. 480484, USA, 2000.

[24] Y. Liu, B. Zhou, and S. Fang, "Sliding mode control of PMSM based on a novel disturbance observer," Proceedings of the CSEE, vol. 30 , no. 9, pp. 80-85, 2010.

[25] M. Cui, C. Zhang, and J. Zhu, "Implementation of PMSM speed drive system based on sliding mode control," Journal of Electronic Measurement and Instrument, vol. 26, no. 1, pp. 8492, 2012. 


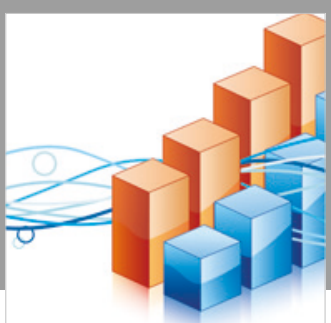

Advances in

Operations Research

\section{-n-m}
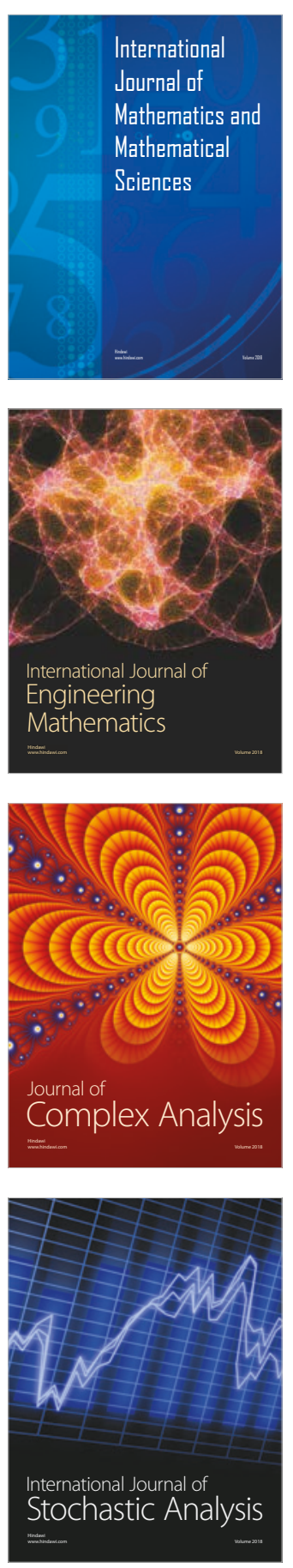
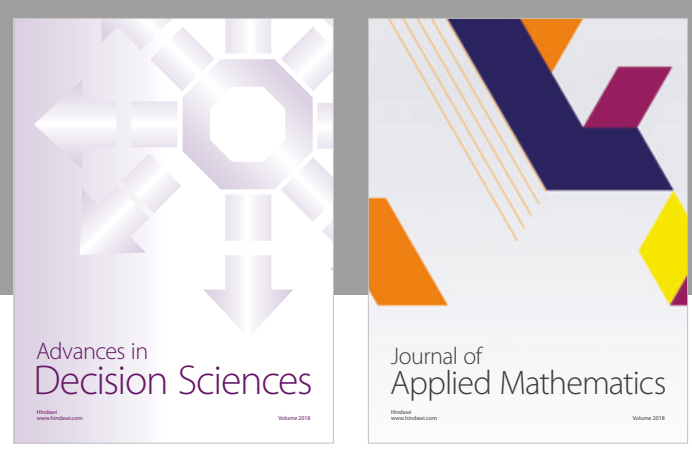

Journal of

Applied Mathematics
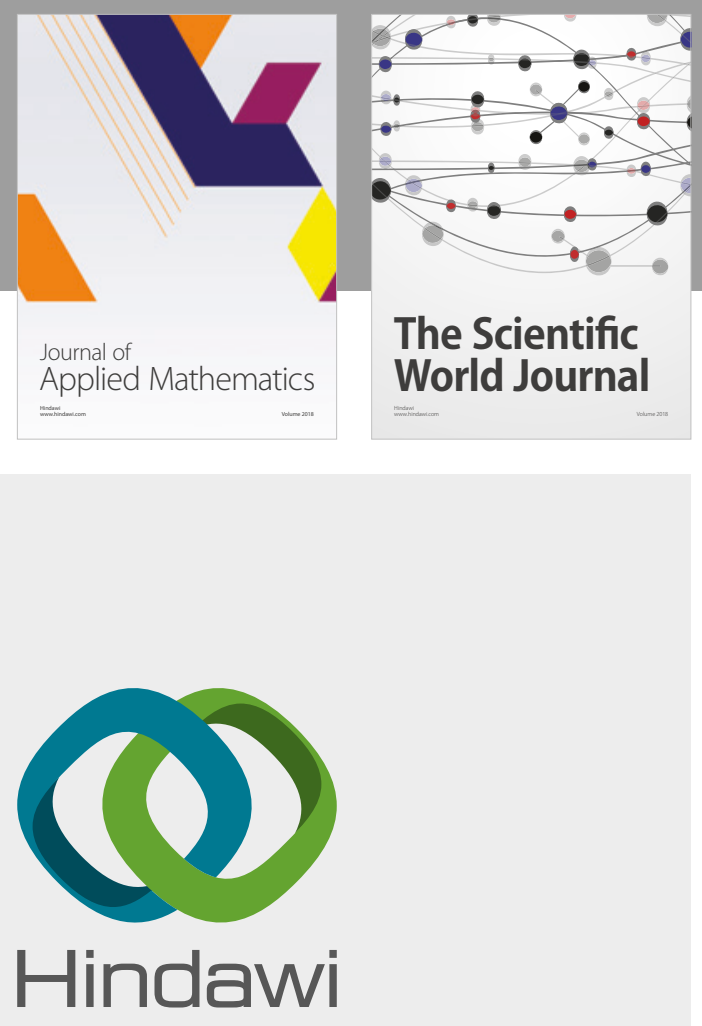

Submit your manuscripts at

www.hindawi.com

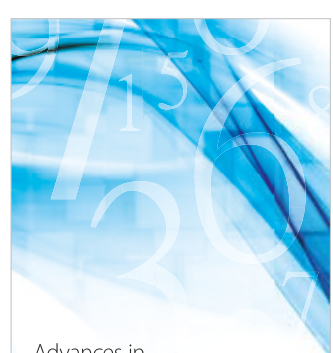

Advances in
Numerical Analysis
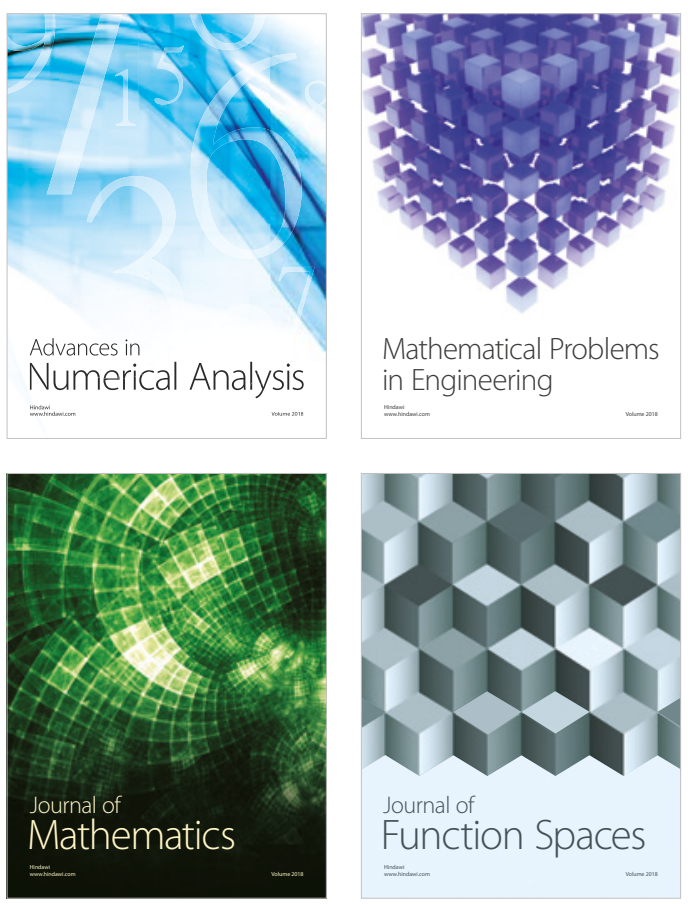

Mathematical Problems in Engineering

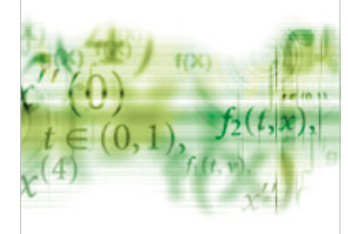

International Journal of

Differential Equations

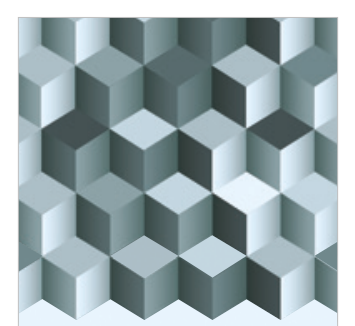

Journal of

Function Spaces

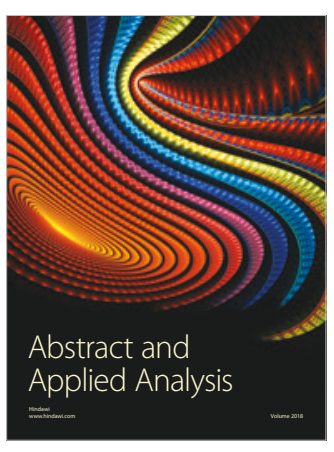

The Scientific

World Journal

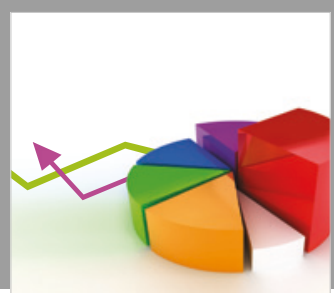

Journal of

Probability and Statistics
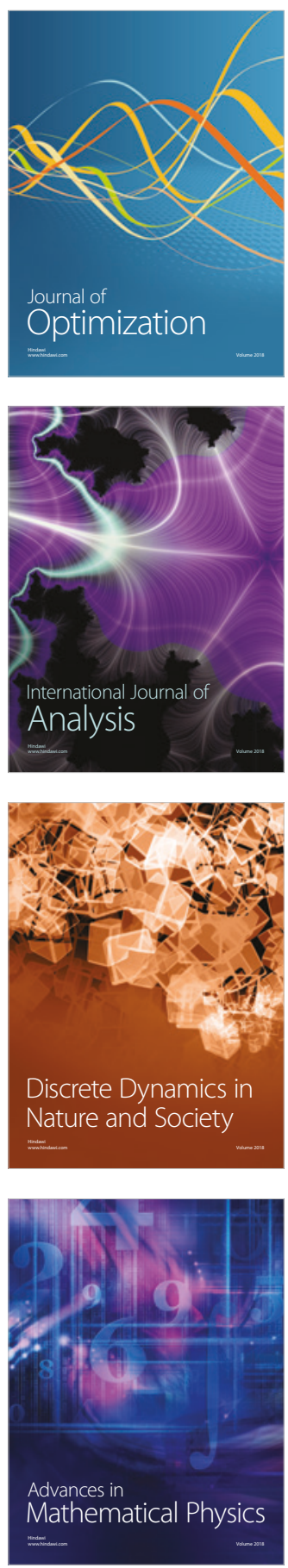